\title{
Acronecrosis with Cold Agglutinin Disease Mimics Diabetic Gangrene
}

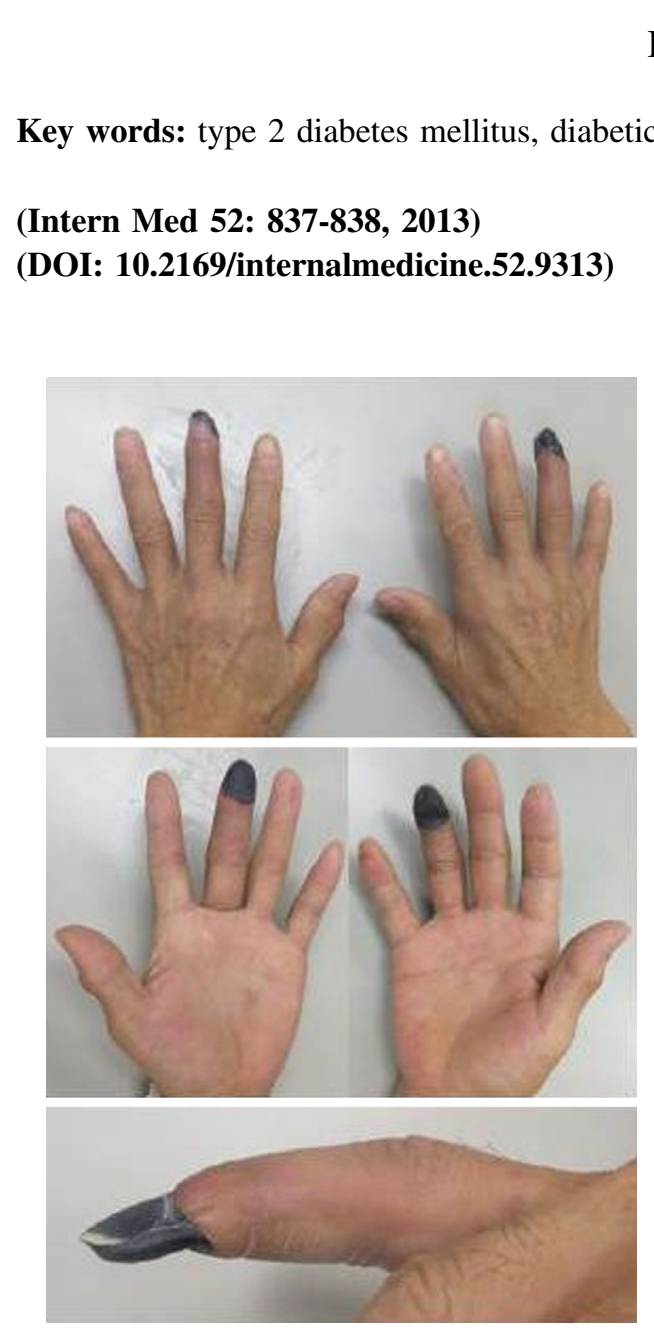

Picture 1.
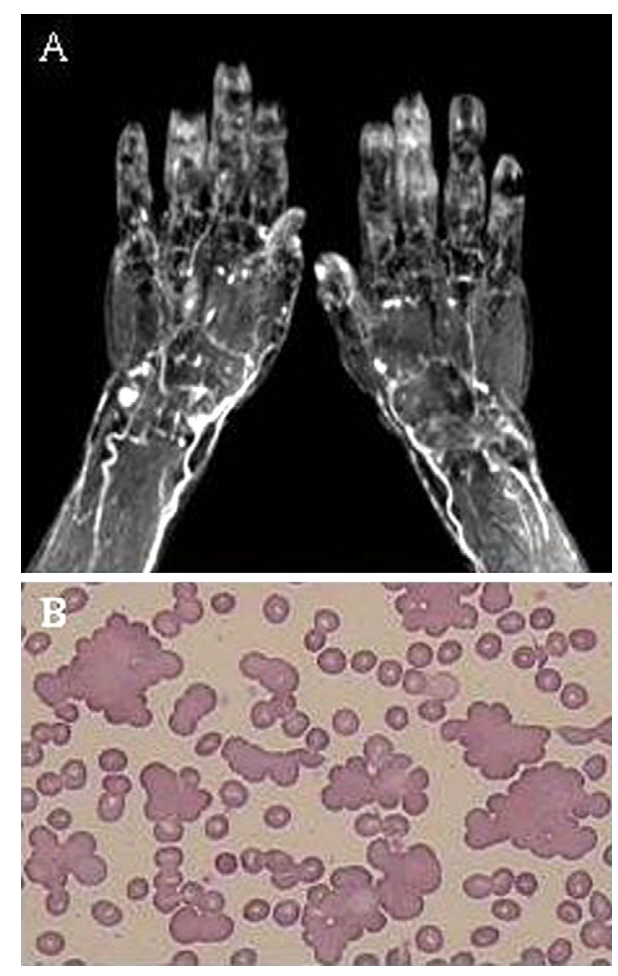

Picture 2.
A 60-year-old man with a 23-year history of untreated type 2 diabetes was referred to our hospital for progressive diabetic gangrene in multiple fingers despite treatment with calcium channel blockers and prostaglandin $\mathrm{I}_{2}$ derivatives (Picture 1). A physical examination and magnetic resonance angiography revealed no apparent obstruction of the arteries of the upper extremities (Picture 2A). Although the patient's glycated hemoglobin level was normal, he had a high plasma glucose levels (417 mg/dL) and massive glucosuria. This discrepancy was considered to be responsible for the patient's hemolytic anemia, rouleau formation (Picture 2B) and positive result for the cold hemagglutination test $(x$ 65,536). This case shows that acronecrosis with cold agglutinin disease can mimic diabetic gangrene (1). It is occasionally difficult to distinguish between ulcers caused by diabetes and those caused by venous occlusion (2). In cases of gangrene, particularly at uncommon sites, the possibility of nondiabetic causes should therefore be considered in patients with diabetes.

The author states that he has no Conflict of Interest (COI).

${ }^{1}$ Department of Internal Medicine, Chiba Rosai Hospital, Japan and ${ }^{2}$ Department of Internal Medicine, Toshiba Rinkan Hospital, Japan Received for publication November 11, 2012; Accepted for publication December 5, 2012

Correspondence to Dr. Hiroaki Iwasaki, iwasaki.har@gmail.com 
Intern Med 52: 837-838, 2013 DOI: 10.2169/internalmedicine.52.9313

\section{References}

1. Berentsen S, Tjønnfjord GE. Diagnosis and treatment of cold agglutinin mediated autoimmune hemolytic anemia. Blood Rev 26:
107-115, 2012.

2. Khan NA, Rahim SA, Anand SS, Simel DL, Panju A. Does the clinical examination predict lower extremity peripheral arterial disease? JAMA 295: 536-546, 2006.

(C) 2013 The Japanese Society of Internal Medicine http://www.naika.or.jp/imonline/index.html 